\title{
Surface Modification of Cucr25 Alloy with Cr Coatings Treated by High Current Pulsed Electron Beam
}

\author{
Zhiming Zhou ${ }^{1}$, Hongmei Xiao ${ }^{1}$, Weijiu Huang ${ }^{1}$, Jian $\mathrm{Tu}^{1}$, Yuanfang Chen ${ }^{1}$, Zhipei Xiao ${ }^{1}$, Tianxing Luo ${ }^{1}$, \\ Yaping Wang ${ }^{2}$ \\ ${ }^{1}$ School of Materials Science and Engineering, Chongqing University of Technology, 400054, China; \\ ${ }^{2}$ School of Science, Xi' an Jiaotong University, 710049, China
}

\begin{abstract}
CuCr25 alloy samples in this study were coated with $\mathrm{Cr}$ and irradiated by high current pulsed electron beam (HCPEB) with intermittently increasing pulse numbers from 1 to 100. The results indicated that with HCPEB treatment, initial $\mathrm{Cr}$ particles and coated $\mathrm{Cr}$ layer remelted and distributed nonuniformly in $\mathrm{Cu}$. Meanwhile, The $\mathrm{Cr}$ particles were significantly refined and the solid solubility of $\mathrm{Cr}$ in $\mathrm{Cu}$ increased with raising pulse number. The formation of craters was a remarkable feature under pulse number 30 due to the dynamic thermal field created by HCPEB. Another notable characteristic induced by HCPEB were numerous cracks formed as a result of thermal stresses during irradiation when the pulse number was up to 10 , then the cracks dissolved when the pulse number increased to more than 50 . In addition, a preference of these cracks to $\mathrm{Cr}$ particles instead of $\mathrm{Cu}$ phase has been also noted.
\end{abstract}

Keywords-CuCr25 alloy; microstructure; high current pulse electron beam; surface modification.

\section{INTRODUCTION}

With the exclusive combination of excellent electrical conductivity, high withstand voltage, exceptional current breaking capacity, and long service life, $\mathrm{Cu}-\mathrm{Cr}$ alloy has been considered as the best contact material for vacuum interrupter and extensively applied in medium voltage field [1]. Moreover, as the chemical composition and purity are the pivotal prerequisite to uphold the current-breaking for contact materials due to a segregated second phase compromises the efficiency of the device and promotes the preferential breakdown [2], the grain size and distribution of $\mathrm{Cr}$ is considered critical to reduce chopping currents and sustain the high-voltage breakdown strength capacity [1].

According to some previous work, electron beam evaporation, thermal evaporation [3] and magnetron sputtering [4] are employed in respect to the deposition techniques preparing $\mathrm{Cr}$ thin films. With desirable stability, reproducibility and rather high deposition rate [5], magnetron sputtering has become the most common used methods among all these techniques.

Along with substantial advantages of $\mathrm{CuCr}$ alloys mentioned above, there are also some certain internal defects. The shortcomings of $\mathrm{CuCr}$ composites may be reduced by producing new non-equilibrium structures and solid solutions under some particular conditions. One of the advanced surface treatment methods is a surface modification by using ion, laser and electron beams [6]. Among all the high-power beams, high current pulsed electron beam (HCPEB) is a newly developed but advantageous technique by its high reliability, simplicity and efficiency [7]. HCPEB is characterized by the formation of unique temperature fields concentrated in the heat affected zone (HAZ), and beyond the HAZ in depth, there are stress fields located in the material [8]. Investigations into surface modification effect analysis of $\mathrm{CuCr} 25$ alloy after a fine $\mathrm{Cr}$ layer formed will be further studied in present work.

\section{EXPERIMENTAL}

The material employed in this experiment is a $\mathrm{CuCr} 25$ alloy $(75$ wt. $\% \mathrm{Cu}, 25 \mathrm{wt} \% \mathrm{Cr})$ prepared by vacuum induction melting(VIM) in a protective atmosphere of pure argon. After coarsely milled, the as-prepared $\mathrm{CuCr} 25$ alloy was deposited a Cr film using FJL560A ultrahigh vacuum magnetron sputtering equipment. After magnetron sputtering, an "RITM-2M" type HCPEB machine was applied to exert a surface irradiation with increasing pulse times of $1,10,30,50$, and 100. The conditions of HCPEB are as follows: the electron energy $30 \mathrm{keV}$, the frequency $0.1 \mathrm{~Hz}$, pulse duration $2 \mu \mathrm{s}$. The microstructure and surface morphology after HCPEB treatment were analyzed by JEOL JSM-6460LV scanning electron microscope (SEM).

\section{RESULTS AND DISCUSSION}

The micrograph of Figure 1a illustrates the initial microstructure of $\mathrm{CuCr} 25$ alloy prepared by VIM. As shown in the picture, it comprises coarse $\mathrm{Cr}$ dendrites distributed in $\mathrm{Cu}$ matrix. The micrograph of Figure $1 \mathrm{~b}$ illustrates the cross section after magnetron sputtering coated with $\mathrm{Cr}$ film. It can be found that a $2 \mu \mathrm{m}$ thick Cr layer is uniformly coated on the alloy surface.
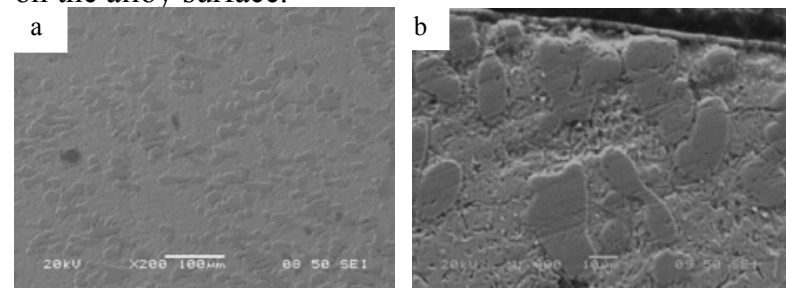

(a) Vacuum induction melting; (b) Magnetron sputtering coating

Figure 1. Micrograph showing the microstructure of $\mathrm{CuCr} 25$ master alloy ( gray $=$ Fe-rich, light $=$ Cu-rich) 

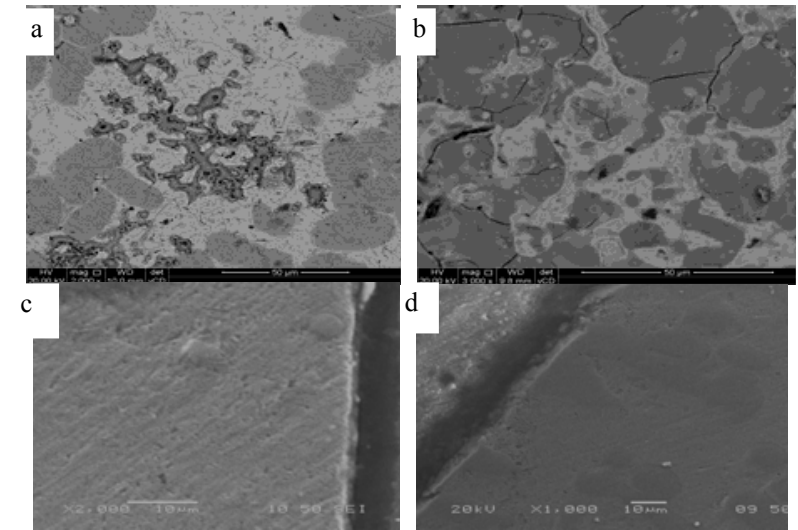

Figure 2.Micrographs illustrating the microstructure of $\mathrm{CuCr} 25$ alloys for different pulse numbers: (a) 1 pulse surface (b) 10 pulses surface

(c) 1 pulse cross-section (d) 10 pulses cross-section

The SEM micrographs of Figure 2 illustrate the surface microstructure of the HCPEB CuCr25 alloys. As indicated in Figure 2a, with one pulse HCPEB-treating, the $\mathrm{Cr}$ layer of $\mathrm{CuCr}$ alloy begins to remelt, distributing in the $\mathrm{Cu}$ substrate ununiformly. While the $\mathrm{Cr}$ phase treated by vacuum induction melting almost remain unchanged. The interface between $\mathrm{Cr}$-rich particles and $\mathrm{Cu}$-rich phase are relatively clear. After ten pulses HCPEB-treatment (shown in Figure 2b), cracks appeared in $\mathrm{Cr}$ particles on the surface, the interface between $\mathrm{Cr}$-rich particles and $\mathrm{Cu}$-rich phase began to be fuzzy. Figure $2 \mathrm{c}$ and Figure $2 \mathrm{~d}$ show the microstructures of the cross-section respectively for 1 pulse and 10 pulses, remelting exists in both $\mathrm{Cu}$-rich matrix and the surface of $\mathrm{Cr}$ phase by $2-3 \mu \mathrm{m}$ in thickness.
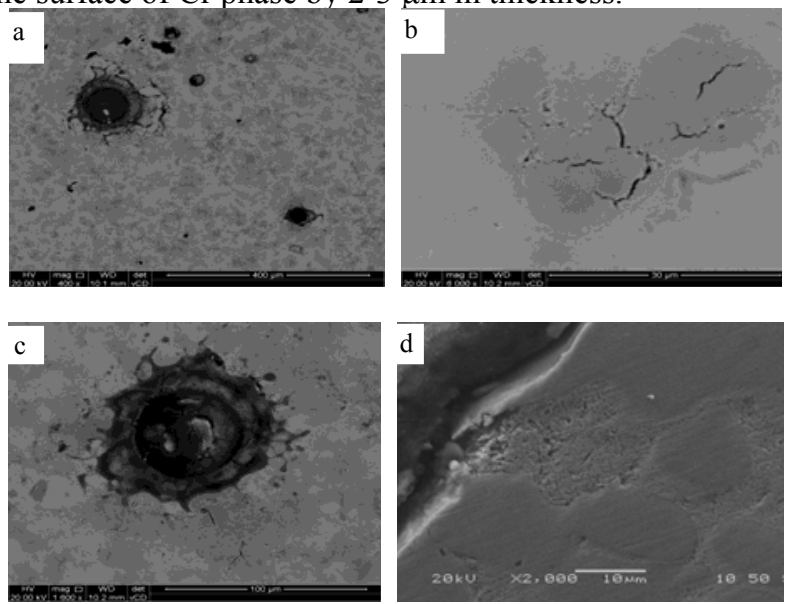

(a) Surface (b) magnified of Cr particles (c) magnified of craters (d) cross-section

Figure 3. Micrographs illustrating the microstructure of $\mathrm{CuCr} 25$ alloys for 30 pulses

Figure 3 shows the secondary electron images of HCPEB-treated specimens under 30 pulses. $\mathrm{Cr}$ phase on the surface of the alloy is greatly refined according to these images, and craters appeared as a unique feature. Figure $3 \mathrm{~b}$ shows the microstructure of magnified $\mathrm{Cr}$ particles, we can see that the interface between $\mathrm{Cr}$-rich particles and $\mathrm{Cu}$ - rich phase become fairly fuzzy. Besides, many micro-cracks appeared in the $\mathrm{Cr}$ particles, and the $\mathrm{Cr}$ phase is further refined. Figure $3 \mathrm{c}$ illustrates the microstructure of magnified crater eruptions, we can see craters formed in Cr-rich phase and $\mathrm{Cr}$ spattered around after melting. In addition, cracks appeared in $\mathrm{Cr}$ phase. Figure $3 \mathrm{~d}$ gives the microstructure of cross-section, the remelt layer is $3-5 \mu \mathrm{m}$ in thickness, and craters appeared in the remelting layer.
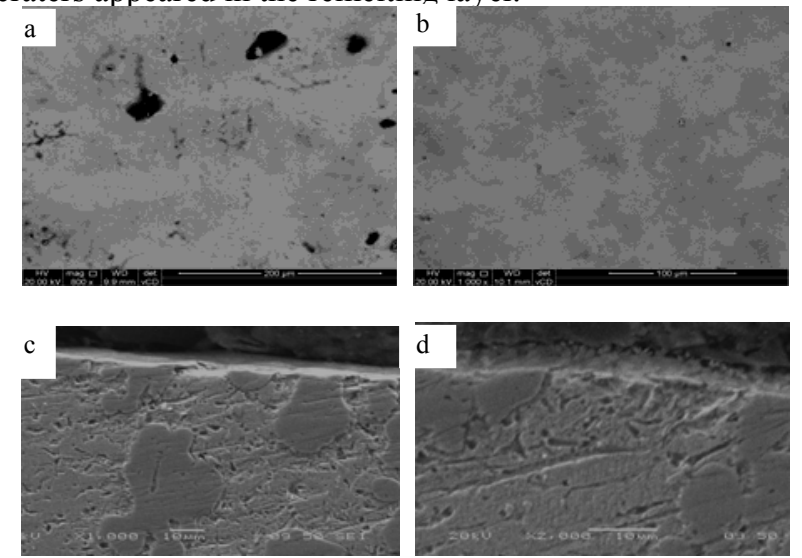

(a)surface of 50 pulses (b)surface of 100 pulses (c)cross-section of 50 pulses (d)cross-section of 100 pulses

Figure 4. Micrographs illustrating the microstructure of $\mathrm{CuCr} 25$ alloys for different pulse numbers

The Microstructures of $\mathrm{CuCr} 25$ alloy when the irradiation times increase to 50 and 100 are shown in Figure 4. From Figure $4 \mathrm{a}$ and Figure $4 \mathrm{~b}$, the interface between $\mathrm{Cr}$-rich particles and $\mathrm{Cu}$-rich phase become fuzzier, and the former micro-cracks in $\mathrm{Cr}$ particles is disappeared. From the cross-section images we can see the thickness of the remelting layer appeared on the surface is about $3-10 \mu \mathrm{m}$ (shown in Figure 4c and Figure 4d).

In this investigation, when the pulse number is one, the $\mathrm{Cr}$ layer on the surface remelts due to the relatively low energy and thermal stress. Furthermore, as the irradiation energy of HCPEB is inhomogeneous, $\mathrm{Cr}$ phase presents a random distribution as shown in Figure 2. When the pulse number increases to 10 , with the increase of energy and thermal stress, the relatively larger $\mathrm{Cr}$ particles fracture under thermal stress, as shown in Figure 2b. Both the $\mathrm{Cu}$ and $\mathrm{Cr}$ have remelted and the remelting layer is merely about $3 \mu \mathrm{m}$ (as shown in Figure $2 \mathrm{c}$ and Figure $2 \mathrm{~d}$ ). When further increase the pulse number from 10 to 30 , on one hand, since the heat of HCPEB can make the alloy surface remelt repeatedly, the interface between Cr-rich particles and $\mathrm{Cu}$-rich phase become fuzzy; on the other hand, because of the heat generated by HCPEB bombardment, substantial thermal stress will be produced, thus making it possible to the formation of cracks in $\mathrm{Cr}$ particles [9] as shown in Figure $3 \mathrm{~b}$. When the electron beam irradiate in the original chapped $\mathrm{Cr}$ phase again, coarse craters or cavities will occur on the alloy surface as shown in Figure 3c. Moreover, sputtering phenomenon and cracks will be found in the crater. The craters are the consequence of the eruption of pools of melted metal and nucleated at structural defect like 
grain boundaries and dislocation sliding bands [10]. With the increase of pulse number, $\mathrm{Cr}$ phase become finer and the solid solubility is increased. Besides, the remelt $\mathrm{Cu}$-rich phase will fill the original cracks generated in $\mathrm{Cr}$ particles. As a result, the interface between the $\mathrm{Cr}$ phase and the $\mathrm{Cu}$ substrate is increasingly fuzzy, Cr grain size become finer as shown in Figure 4, which will improve the withstand voltage strength and other properties.

\section{CONCLUSIONS}

Studies on the microstructure evolution occurring in the modified surface and morphologies of pre-treated and irradiated samples indicate that there are possibilities to develop efficient methods for the surface modification of materials with HCPEB technique. We can draw the following conclusions:

1) The $\mathrm{Cr}$ particles were significantly refined and the solid solubility of $\mathrm{Cr}$ in $\mathrm{Cu}$ gradually increased with the increasing pulse number.

2) After HCPEB treatment, the irradiated surface partially melted and then craters were formed in these domains. The formation of surface craters was a remarkable feature under pulse number 30 due to the non-equilibrium temperature filed and different stresses exerted by HCPEB.

3) Cracks formed under thermal stresses during electron beam irradiation would dissolve when the pulse number increased to more than 50 .

\section{ACKNOWLEDGEMENTS}

This study is financially supported by the National
Natural Science Foundation of China under grant No. 51101177, 51171146 and 51171216, the Natural Science Foundation of Chongqing under grant No. cstc2012jjA245.

\section{REFERENCES}

[1] A.Lamperti, P.M.Ossi, V.P.Rotshtein, Surface analytical chemical imaging and morphology of $\mathrm{Cu}-\mathrm{Cr}$ alloy, Surface \& Coatings Technology, 200, pp.6373-6377, 2006.

[2] Wang Y., Ding B., IEEE Trans. Compon. Packag. Technol, 22, pp. $467,1999$.

[3] Zhang Heng, Zhou Yun, et al., Fabrication of Micro-grating structures by nanosecond laser ablation of Chrome film on glass substrate, Acta Photonica Sinica, 38(2), pp.241-244,2009.

[4] CHIANG K T K,WEI R H. Growth morphology and corrosion resistance of magnetron sputtered $\mathrm{Cr}$ films, Surface \& Coatings Technology, 206(7), pp.1660-1665,2011.

[5] Pei Yu, Lin Li-Mei, et al., Effect of passing electric current on the electrical and optical properties of ITO films in air, Surface Review and Letters, 16(6), pp.887-893,2009.

[6] A.D. Pogrebnjak, S.Bratushka, et al., A review of mixing processes in $\mathrm{Ta} / \mathrm{Fe}$ and $\mathrm{Mo} / \mathrm{Fe}$ systems treated by high current electron beams, Nucl. Inst. Meth. Phys. Res., B 145, pp.373-390,1998.

[7] G.E. Ozur, D.I. Proskurovsky, V.P. Rotshtein, A.B. Markov, Laser Particle Beams,21, pp.157,2003.

[8] Hao Sheng-Zhi, Bo Gao, et al., Surface modification of steels and magnesium alloy by high current pulsed electron beam, Nucl. Inst. Meth. Phys. Res., B 240, pp,646-652. 2005.

[9] Ying Qin, Zou Jian-Xin, et al., Temperature-stress fields and related phenomena induced by a high current pulsed electron beam. Nucl. Inst. Meth. Phys. Res.,B225, pp.544-554,2005.

[10] Guan Q.F., Zhang Q.Y., Dong C., et al, Effect of structure defects on the surface craters induced by high current pulsed electron beam, Chin. J. Mater. Res., 19, pp.496,2005. 